Terbit online pada laman web jurnal : http://teknosi.fti.unand.ac.id/

Artikel Penelitian

\title{
Analisis Kelayakan Sistem Monitoring dan Kontrol Lampu Menggunakan Web Server Berbasis Raspberry Pi
}

\author{
Andi Maslan ${ }^{1}$, Hendri $^{1}$ \\ ${ }^{1}$ Universitas Putera Batam, Batam 29432 Indonesia
}

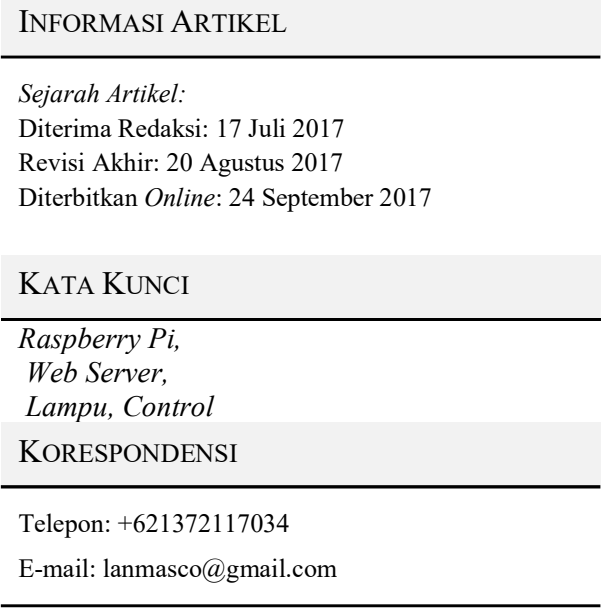

\begin{abstract}
A B S T R A C T
As technology develops progressively over time, system developers continue to strive to create more efficient monitoring systems. The problem that often happens is the control room and light control is currently not utilize an integrated system based web server. Room control systems still utilize large equipment such as televisions and large computers, so that every problem occurs in the room is difficult to control. From these problems then the purpose of this study to create an efficient control system that utilizes super mini-based Raspberry Pi. To create a system based on Raspberry P microcontroller then required an initial observation to perform the feasibility test on the system to be developed. The feasibility test system is the successful monitoring of the room using CCTV (Closed Circuit Television) equipment and control the lamp automatically by using prototyping method. The CCTV feasibility test is viewed from the resolution while the control of room light control is seen from the success of controlling the life of the lights on the test. Based on the testing concluded that the monitoring of the room using Raspberry Pi-based web server is feasible to use, seen the test results when the light control goes smoothly, because the lights controlled through the webserver managed to live and die. Similarly, when monitoring the room with live CCTV also runs well. And while conducting Room monitoring experiments with Webcam at $800 \times 600$ resolution there is a lot of variation value of frame rate sometimes up and down. The up and down frame is caused by an unstable network connection.
\end{abstract}

\section{PENDAHULUAN}

Seiring dengan perkembangan teknologi yang semakin maju dari waktu ke waktu maka pengembang terus berusaha menciptakan sistem pemantauan yang lebih efisien, manusia menciptakan sistem keamanan ruangan dapat berupa sistem pemantauan dapat didukung melalui teknologi CCTV (Closed Circuit Television) yang terhubung komputer dan terintegrasi dengan microcontroller yang dapat diprogram sesuai dengan kebutuhan, sebagai contoh selain dapat memantau ruangan tetapi juga bisa mengendalikan piranti elektronik di ruangan tersebut. Akan tetapi untuk hasil yang optimal dalam melakukan monitoring, CCTV harus dilengkapi dengan Raspberry Pi.

Raspberry $P i$ adalah komputer mikro berukuran kecil yang dikembangkan oleh Raspberry Pi Foundation, Inggris. Untuk itu pengamatan suatu objek menjadi lebih praktis. Dalam mengamati suatu objek tidak perlu dilakukan pengamatan secara langsung dan terus menerus, namun cukup meletakkan suatu kamera yang mengarah pada objek yang diinginkan lalu mengamatinya dari layar monitor. Kebutuhan Komputer single board ini dikembangkan dengan tujuan untuk mengajarkan dasar-dasar ilmu komputer dan pemrograman untuk siswa sekolah di seluruh dunia. Namun saat ini penggunaan Raspberry Pi masih sedikit karena kurangnya pengetahuan akan Raspberry Pi sehingga pada umumnya perusahaan besar hanya menggunakan CCTV standard tanpa adanya Raspberry Pi. Masalah yang sering terjadi seperti kerusakan lampu dan juga lambatnya respon dari maintainer karena hanya dapat mengetahui masalah tersebut dari ruang khusus.

Penggunaan ruang server yang biasa digunakan pada sistem CCTV yang sering digunakan saat ini dapat dikurangi implementasinya karena sistem ini tidak memerlukan ruang server. Raspberry Pi yang berukuran kecil dapat ditempatkan dimana saja [1].

Raspberry Pi layak dijadikan web server terutama untuk aplikasiaplikasi web server berikut: Apache, Lighttpd, dan Nginx. Ketiga aplikasi web server ini dapat menangani 100 permintaan simultan, baik untuk halaman-halaman statis maupun halamanhalaman dinamis, dalam kurun waktu 1 detik [2]. Selain itu alat elektronika tegangan $\mathrm{AC}$ sekaligus oleh delapan relay dengan setiap relay nya yang mampu menanggung beban maksimal 
sebesar 800 watt dengan menggunakan catu daya pada Raspberry $P i$ yang memiliki minimal kuat arus 0,7 ampere. [3]

\section{TINJAUAN PUSTAKA}

Jaringan komputer adalah sebuah kumpulan dari komputer, printer, dan peralatan lainnya yang terhubung dalam satu kesatuan dan membentuk suatu sistem tertentu. Informasi bergerak melalui kabel atau tanpa kabel sehingga memungkinkan pengguna jaringan komputer dapat saling bertukar informasi (data), mencetak data pada printer yang sama dan dapat secara simultan menggunakan program aplikasi yang sama[4].

Raspberry Pi merupakan bagian dari jaringan computer yang memiliki ukuran sebesar kartu kredit yang dikembangkan di Inggris oleh Raspberry Pi Foundation. Gagasan di balik sebuah komputer kecil dan murah untuk anak-anak muncul pada tahun 2006. Ide ini muncul ketika beberapa mahasiswa Laboratrium Komputer di Universitas Cambridge, yakni eben Upton, Rob Mullins, Jack Lang, dan Alan Mycroft, melakukan eksperimen pada anak-anak pada tahun 90an mengenai pengalaman si anak menjadikan mereka sebagai seorang progammer. sedangkan, sekitar tahun 2000-an agak berbeda, rata-rata mereka hanya melakukan desain web saja. Ternyata perubahan tersebut terjadi karena dilatarbelakangi oleh beberapa parameter, seperti penggunaan kurikulum pembelajaran tentang microsoft word dan excel, menulis halaman web, atau munculnya PC rumah dan games. Perangkat Raspberry PI terlihat seperti motherboard, dengan berbagai chip dan port. Spesifikasi sebuah Raspberry PI adalah sebagai berikut: CPU ARM $700 \mathrm{MHz}$, RAM $512 \mathrm{Mb}$ (untuk Raspberry Pi Rev.B), harddisc-nya berupa SD card minimal 4 GB dengan Class 10, dua buah port USB, 1 port HDMI, 1 port video (RCA), 1 buah port audio, 1 port LAN (RJ45) dan beberapa pin GPIO (General Purpose Input Output). Sebagai sebuah komputer mini dengan spesifikasi perangkat keras yang terbatas, maka untuk sistem operasinya juga bertipe ringan. Untuk sistem operasi yang dapat berjalan di Rapsberry adalah Linux dengan distro sebagai berikut: Raspbian, Arch Linux, Risc OS, Pidora dan OpenElec. [5]

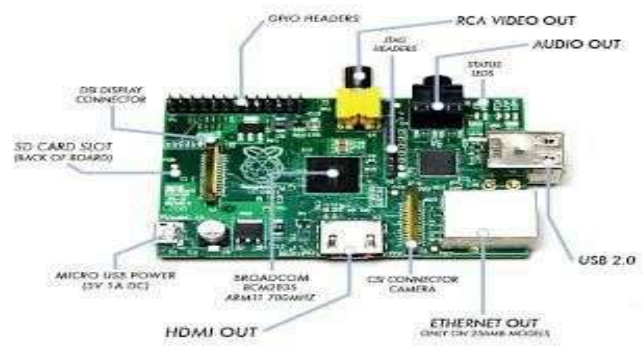

Gambar 1. Perangkat Keras dari Raspberry PI [5]

Raspberry $P i$ adalah platform yang sangat fleksibel, ada banyak hal yang bisa dilakukan dengan Raspberry Pi. Beberapa hal tersebut antara lain:

1. General Purpose Computing

Raspberry $P i$ dapat dijadikan sebagai komputer seperti biasa kita gunakan sehari-hari dengan menghubungkannya ke monitor dan mengatur tampilan grafisnya melalui web browser.

2. Media Belajar Pemrogaman

Di dalam Raspberry $P i$ sudah terdapat interpreter dan compiller dari berbagai bahasa pemrograman seperti $\mathrm{C}$, Ruby, Java, Perl dan lain-lain karena sebenarnya tujuan awal Raspberry $P i$ adalah untuk mendorong anak-anak untuk belajar pemrogaman.

3. Project Platform

Raspberry $P i$ mempunyai kamampuan untuk berintegrasi dengan alat-alat elektronik lain.

Misalnya, Raspberry Pi bisa digunakan sebagai remote AC.

4. Media Center

Karena Raspberry Pi memiliki port HDMI dan audio/video, maka Raspberry Pi dapat dengan mudah dihubungkan ke monitor. Keunggulan didukung oleh kekuatan prosesor Raspberry Pi yang cukup untuk memutar video full screen yang high definition. Selain itu, di dalam Raspberry P $i$ sendiri sudah terdapat XBMC (media player) yang mensupport berbagai macam format media file.[6]

Untuk menjalankan fungsi Raspberry Pi secara keseluruhan, dibutuhkan sistem operasi yang mendukung fungsi dan performa RasPi. Berikut daftar sistem operasi yang mendukung raspberry pi

1. Raspian

Sistem operasi ini merupakan sistem operasi berbasis Debian khusus untuk Raspberry pi.

2. Pidora

Pidora merupakan sistem operasi Fedora berbasis Linux yang dapat dijalankan di Raspberry Pi.

3. OpenElec

OpenElec atau Open Embedded Linux Entertainment Center adalah sistem operasi pada Raspberry Pi berbasis Linux yang dirancang untuk mengubah Raspberry Pi menjadi sebuah pusat media XBMC.

4. RaspBMC

RaspBMC merupakan perpaduan antara Raspbian dengan XBMC.Fungsinya yaitu sebagai pusat media dalam sebuah sistem operasi.

5. RISC OS

RISC OS merupakan sistem operasi yang dirancang khusus untuk prosesor ARM.

6. Arch Linux ARM

Arch Linux ARM merupakan sistem operasi Arch Linux yang digunakan pada Raspberry

Pi.

Kata "PI" pada Raspberry Pi merupakan slang yang merujuk pada "Python". Oleh karenanya, tepat dikatakan bahwa python adalah bahasa natural Raspberry PI. Python merupakan bahasa pemrograman yang freeware atau perangkat bebas dalam arti sebenarnya, tidak ada batasan dalam penyalinannya atau mendistribusikannya. Lengkap dengan source code, debugger dan profiler, antarmuka yang terkandung di dalamnya untuk pelayanan antarmuka, fungsi sistem, GUI (antarmuka pengguna grafis), dan basis datanya. Python menjadi bahasa resmi yang terintegrasi dalam Raspberry Pi.[7] 
Sedangkan Web server adalah sebuah aplikasi server yang melayani permintaan HTTP atau HTTPS dari browser dan mengirimkannya kembali dalam bentuk halaman-halaman web [9]. Halaman-halaman web yang dikirim oleh web server biasanya berupa file-file HTML dan CSS yang nantinya akan diparsing atau ditata oleh browser sehingga menjadi halamanhalaman web yang bagus dan mudah dibaca. Cara kerja dari web server sebenarnya sangat mudah dipahami. Proses yang akan terjadi pada browser adalah browser akan membentuk koneksi dengan web server, meminta halaman website dan menerimanya. Web server kemudian mengecek permintaan tersebut apakah tersedia atau tidak. Apabila tersedia, maka web server akan mengirimkan data kepada browser.[8]

Adapun kerangka pemikiran dalam penelitian ini berdasarkan permasalahan dan tinjauan pustaka disajikan pada gambar berikut:

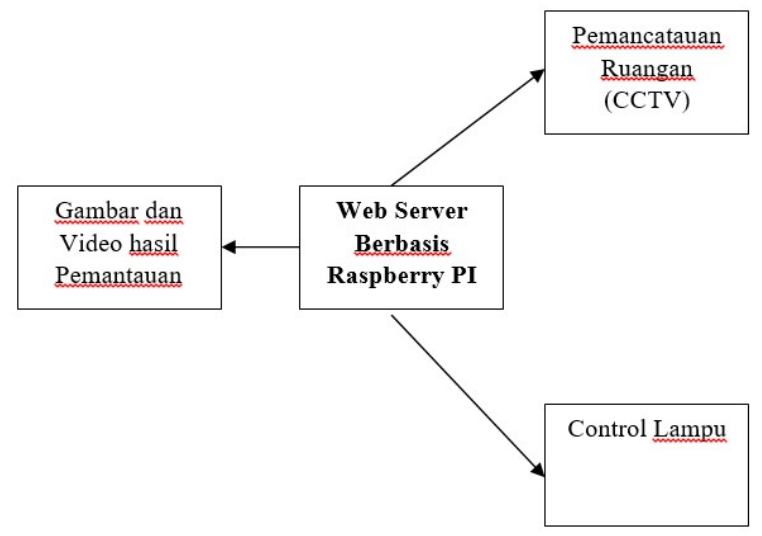

Gambar 2. Kerangka Berfikir

\section{METODOLOGI}

Metodologi yang digunakan dalam penelitian ini adalah metode prototyping. Metode ini mengekspresikan dan mendeskripsikan pemanfaatan pemanfaatan Raspberry dalam melakukan monitoring CCTV dan Control Lampu. Fase-fase yang dilakukan untuk pengujian kelayakan webserver berbasis Raspberry yaitu 1) Pengamatan, 2) Pengumpulan Data, 3) Analisis Data dan Pengujian dan 4) hasil pengujian [10]. Data dikumpulkan dengan melakukan observasi secara langsung terhadap objek yang diamati. Pengamatan dilakukan selama tiga hari berturut-turut dengan mencatat variasi frame rate, delay dan motion dari lampu yang digunakan. Sedangkan Pemantauan ruangan memanfaatkan CCTV yang terhubung langsung dengan system Raspberry PI memperhatikan framerate dari live streaming. Gambaran Object monitoring dalam penelitian ini adalah segala sesuatu yang akan dijadikan subjek atau objek penelitian yang dikehendaki peneliti dapat dilihat dari gambar berikut :

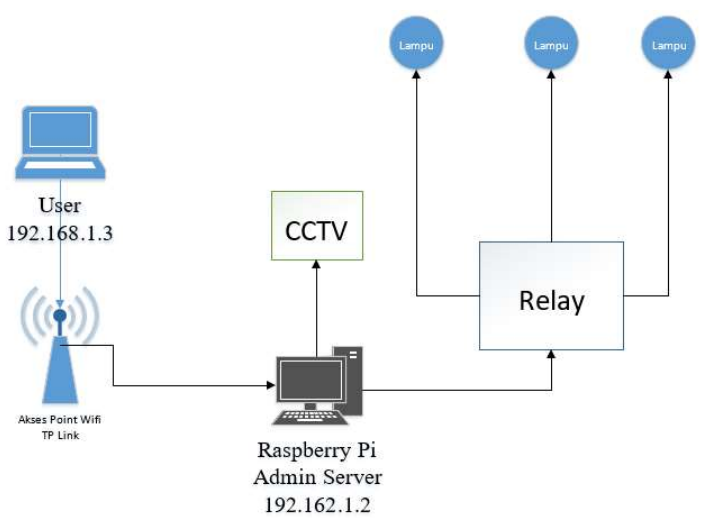

Gambar 3. Object Monitoring

Gambar 5 menunjukan simulasi dari pemantauan ruangan dan kontrol lampu menggunakan webserver berbasis Raspberry PI. Pemantauan dapat dilakukan oleh user dan admin, pemantauan yang dilakukan oleh admin mengkontrol dan memperbaiki webserver apabila terjadi kerusakan sedangkan user hanya dapat melakukan pemantauan ruangan dan juga kontrol lampu tapi tidak dapat melakukan perbaikan webserver seperti admin.

\section{HASIL DAN PEMBAHASAN}

Hasil pengujian untuk melihat apakah Raspberry $P i$ layak untuk menjalankan aplikasi web server, dengan cara pengujian live streaming webcam, yang bertujuan untuk mengetahui apakah library motion yang digunakan untuk fitur live streaming webcam berpengaruh terhadap kualitas live streaming berdasarkan konfigurasi Frame Per Second (fps) yang digunakan. Pengujian ini dilakukan dengan mengubah konfigurasi framerate yang terdapat pada library motion yang digunakan pada proses live streaming. Variasi framerate yang digunakan adalah $5 \mathrm{fps}, 15$ fps, 25 fps, 35fps, dan 45 fps. Dari hasil percobaan diatas didapatkan data pengujian sebagai berikut:

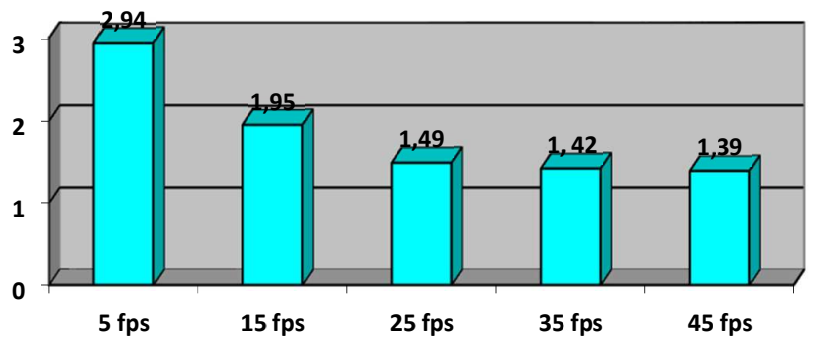

Gambar 4. Hasil pengujian variasi fps pada webcam

Dari tabel hasil pengujian variasi framerate pada webcam menjelaskan bahwa konfigurasi framerate pada motion berpengaruh terhadap kualitas live streaming webcam. semakin tinggi framerate maka akan semakin kecil delay pada fitur live streaming. Pada pengujian 35 fps dan 45 fps tidak terjadi perbedaan delay yang signifikan dikarenakan spesifikasi dari webcam yang digunakan memiliki framerate $30 \mathrm{fps}$ sehingga penggunaan framerate diatas $30 \mathrm{fps}$ tidak terlalu berpengaruh terhadap delay dari fitur live streaming. Adanya delay sendiri 
pada fitur live streaming webcam disebabkan oleh proses transmisi dari satu titik ke titik lain yang menjadi tujuannya.

Tabel 1. Resolusi dan Frame Rate

\begin{tabular}{|c|c|c|c|c|c|}
\hline Resolution & $5 \mathrm{fps}$ & $15 \mathrm{fps}$ & $25 \mathrm{fps}$ & $35 \mathrm{fps}$ & $45 \mathrm{fps}$ \\
\hline $180 \times 120$ & 1,39 & 1,42 & 1,79 & 1,95 & 2,94 \\
\hline $240 \times 180$ & 1,37 & 1,55 & 1,71 & 1,96 & 2,87 \\
\hline $360 \times 240$ & 1,30 & 1,45 & 1,64 & 1,92 & 2,90 \\
\hline
\end{tabular}

Hasil pengujian selang waktu pemrosesan gambar video dengan resolusi gambar mulai dari $180 \times 120$ pixel, 240x180 pixel, $360 \times 240$ pixel dan frame rate mulai dari $5 \mathrm{fps}, 15 \mathrm{fps}, 25 \mathrm{fps}, 35$ fps, 45 fps.

Peneliti melakukan live streaming selama 3 hari untuk mengetahui apakah terjadi perubahan pada delay live streaming.

\section{Hari pertama}

Tabel 2. Hasil Pengujian Variasi FPS Pada Webcam

\section{Frekuensi Frame Rate (fps) Delay (s)} (Hz)

\begin{tabular}{ccc}
\hline $\mathbf{1}$ & 5 & 2,93 \\
\hline $\mathbf{2}$ & 15 & 1,96 \\
\hline $\mathbf{3}$ & 25 & 1,45 \\
\hline $\mathbf{4}$ & 35 & 1,44 \\
\hline $\mathbf{5}$ & 45 & 1,36 \\
\hline
\end{tabular}

Pada hari pertama live streaming dengan resolusi $800 \times 600$ dengan berbagai frame per rate, hasil live streaming tidak mengalami perubahan seperti pada live streaming sebelumnya.

2. Hari kedua

Tabel 3. Hasil Pengujian Variasi FPS Pada Webcam

\begin{tabular}{ccc}
\hline $\begin{array}{c}\text { Frekuensi } \\
(\mathbf{H z})\end{array}$ & $\begin{array}{c}\text { Frame Rate } \\
\text { (fps) }\end{array}$ & Delay $(\mathbf{s})$ \\
\hline $\mathbf{1}$ & 5 & 3,04 \\
\hline $\mathbf{2}$ & 15 & 2,01 \\
\hline $\mathbf{3}$ & 25 & 1,55 \\
\hline $\mathbf{4}$ & 35 & 1,42 \\
\hline $\mathbf{5}$ & 45 & 1,39 \\
\hline
\end{tabular}

Pada hari kedua live streaming dengan resolusi 800x600 dengan variasi frame rate terjadi penambahan nilai delay pada frame rate 5 fps menjadi 3,04 s, pada frame rate 15 menjadi $2,01 \mathrm{~s}$, dan pada frame rate 25 menjadi $1,55 \mathrm{~s}$, sedangkan pada frame rate 35 menjadi $1,42 \mathrm{~s}$, dan frame rate 45 menjadi $1,39 \mathrm{~s}$. Terjadi penambahan dan pengurangan nilai delay disebabkan oleh koneksi jaringan tidak stabil.

\section{Hari Ketiga}

Tabel 4. Hasil pengujian variasi fps pada webcam

\begin{tabular}{ccc}
\hline $\begin{array}{c}\text { Frekuensi } \\
(\mathbf{H z})\end{array}$ & Frame Rate (fps) & Delay (s) \\
\hline $\mathbf{1}$ & 5 & 2,91 \\
\hline $\mathbf{2}$ & 15 & 1,98 \\
\hline $\mathbf{3}$ & 25 & 1,46 \\
\hline $\mathbf{4}$ & 35 & 1,45 \\
\hline $\mathbf{5}$ & 45 & 1,31 \\
\hline
\end{tabular}

Pada hari ketiga live streaming nilai delay pada frame rate $5 \mathrm{fps}$, $15 \mathrm{fps}, 25 \mathrm{fps}$, dan $45 \mathrm{fps}$ terjadi penurunan menjadi 2,91 s untuk frame rate $5 \mathrm{fps}, 1,98 \mathrm{~s}$ untuk frame rate $15 \mathrm{fps}, 1,46 \mathrm{~s}$ untuk frame rate $25 \mathrm{fps}$, dan untuk $45 \mathrm{fps}$ juga menurun menjadi 1,31 $\mathrm{s}$, sedangkan pada frame rate mengalami penambahan nilai delay menjadi $1,45 \mathrm{~s}$ dari hari pertama hingga hari ketiga live streaming.

Pengujian Hasil Tampil Pemantauan Ruangan.

Pengujian ini dilakukan untuk mengetahui apakah peralatan input dan output sudah berfungsi dengan baik atau belum. Lalu seorang admin melakukan akses untuk mengetahui apakah aplikasi terhubung ke raspberry pi maka input perintah pada command prompt seperti dibawah ini:

1. cek apakah usb camera ter-detetct raspberry pi@raspberrypi \$ sudo su - root root@raspberrypi: \# 1susb root@raspberrypi: \# dmesg | grep video

2. install paket motion root@raspberrypi: \# apt-get update root@raspberrypi: \# apt-get install motion

3. edit/etc/motion/motion.conf tempat mengubah framerate/height/weight

4. jalankan servicenya motion root@raspberrypi: \# /etc/init.d/motion star

Motion atau perintah dalam webserver raspberry pi berjalan dengan baik seperti gambar dibawah ini.

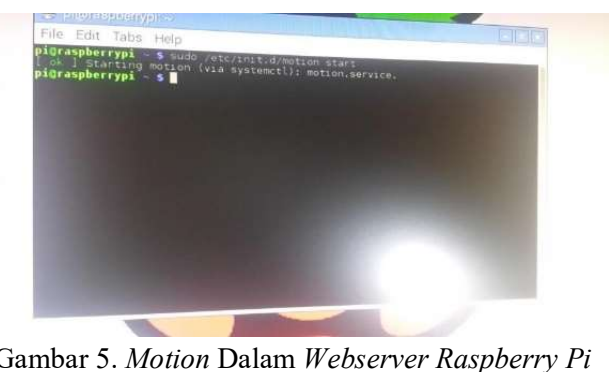

Pengujian ini dilakukan untuk mengetahui apakah peralatan input dan output sudah berfungsi dengan baik atau belum, lalu pengujian sistem dilakukan untuk mengetahui tingkat keberhasilan sistem kontrol lampu, Setelah raspberry siap digunakan, kita harus mengaktifkan GPIO raspberry, seorang admin melakukan akses untuk mengetahui apakah aplikasi terhubung ke raspberry pi maka input perintah pada command prompt seperti dibawah ini:

1. Menginstall Webserver Apache sudo apt-get update sudo apt-get -y upgrade

sudo apt-get -y install openssh-server

https://doi.org/10.25077/TEKNOSI.v3i2.2017.285-290 
sudo apt-get -y install python sudo apt-get -y install pythondev sudo apt-get -y install apache2 sudo apt-get -y install libapache2-mod-wsgi sudo apt-get -y install libapache2mod-proxy-html

2. Coding membuat GPIO file akses pada aplikasi command prompt Code:

echo $17>$ /sys/class/gpio/export echo $18>$ /sys/class/gpio/export echo $22>$ /sys/class/gpio/export

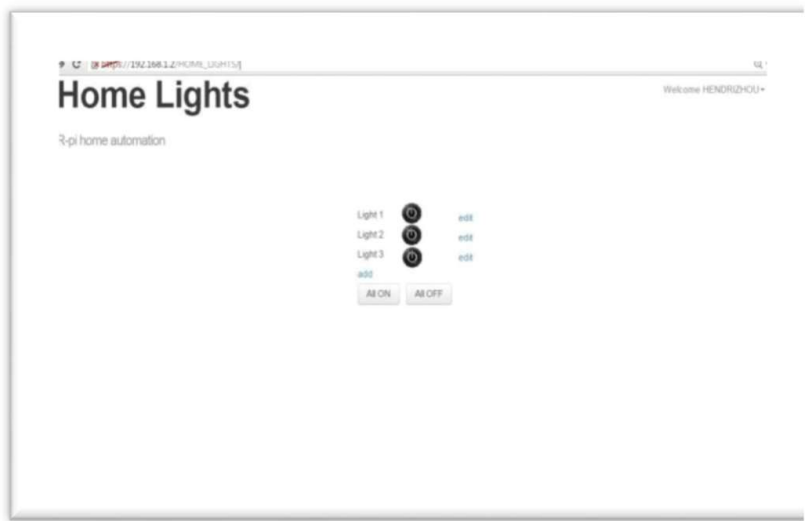

Gambar 6. Tampilan webserver Kontrol lampu

3. Untuk melakukan On / Off pada Lampu kita memasuki 2 coding tersebut kedalam website : Lampu ke 1

echo in >/sys/class/gpio/gpio17/direction echo out >/sys/class/gpio/gpio17/direction Lampu ke 2 echo in >/sys/class/gpio/gpio18/direction echo out $>$ /sys/class/gpio/gpio18/direction Lampu ke 3 echo in $>$ /sys/class/gpio/gpio19/direction echo out >/sys/class/gpio/gpio19/direction

Setelah coding dimasukan maka dilakukan percobaan kontrol lampu pada lampu pertama, kedua, dan ketiga seperti gambar di bawah ini:

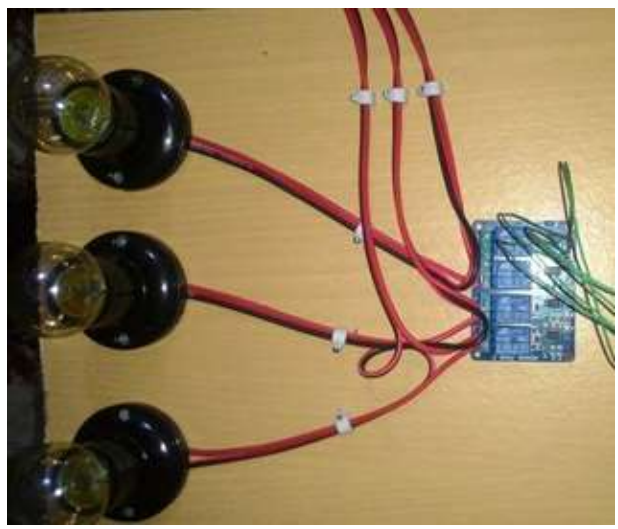

Gambar 7. Lampu terhubung pada raspberry pi

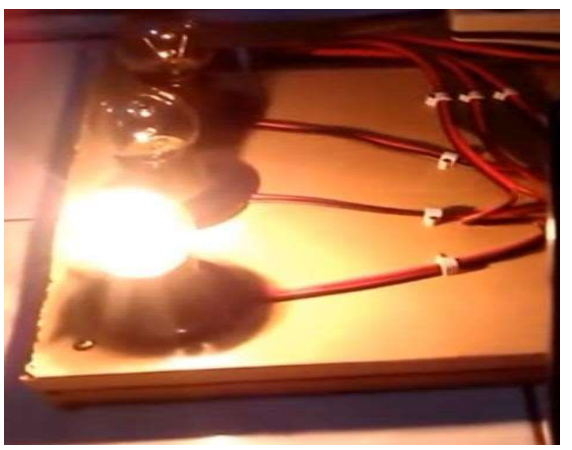

Gambar 8. Percobaan lampu pertama

Seperti pada gambar 15 menampilakn tombol on/off pada webserver lalu dilakukan percobaan untuk menghidupkan lampu pertama. Percobaan pada lampu pertama pada kontrol lampu pada webserver berbasis raspberry pi berhasil menyala.

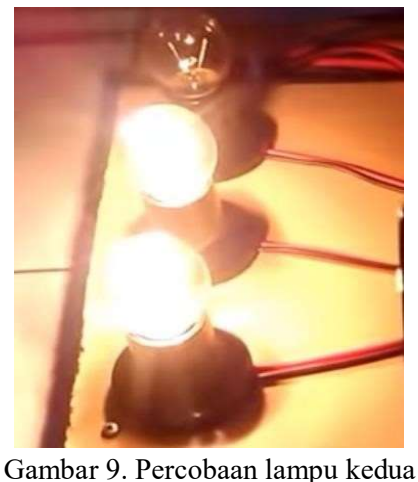

Seperti pada gambar 6 menampilakn tombol on/off pada webserver lalu dilakukan percobaan untuk menghidupkan lampu kedua. Percobaan lampu kedua menggunakan kontrol lampu pada webserver berbasis raspberry pi berhasil menyala.

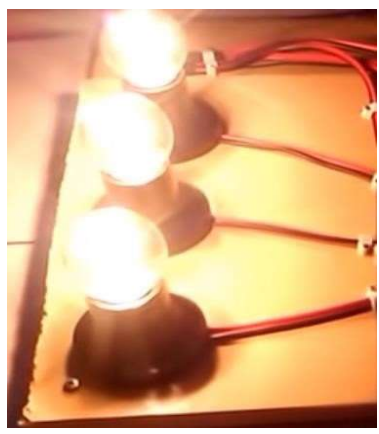

Gambar. 10 Percobaan lampu ketiga

Seperti pada gambar 6 menampilkan tombol on/off pada webserver lalu dilakukan percobaan untuk menghidupkan lampu ketiga. Percobaan terakhir pada lampu ketiga pada kontrol lampu pada webserver berbasis raspberry pi berhasil menyala, dan dapat disimpulkan bahwa percobaan kontrol lampu pada webserver berbasis raspberry pi berjalan lancar. 
Uji kelayakan penggunaan rashberry Pi dapat berjalan dengan baik dengan memanfaatkan webserver sebagai pengontrol kualitas camera pada saat merekam suatu objek dan melakukan control terhadap hidup mati lampu didalam suatu ruangan. Dan ini mememiliki perbedaan dengan penelitian sebelumnya yang berkaitan dengan Kelayakan Raspberry Pi and Mition dari cara kerja dan studi kasus yang dilakukan.

\section{KESIMPULAN}

Berdasarkan hasil penelitian maka dapat disimpulkan bahwa Pemantauan ruangan menggunakan web server berbasis Raspberry $P i$ layak digunakan, dilihat hasil pengujian pada saat kontrol lampu berjalan lancar, karena lampu yang dikontrol melalui webserver berhasil hidup dan mati. Begitu juga pada saat melakukan monitoring ruangan dengan CCTV secara live juga berjalan dengan baik. Dan pada saat melakukan percobaan monitoring Ruangan dengan Webcame pada resolusi 800 x 600 terjadi banyak pariasi nilai frame rate terkadang naik dan turun. Frame yang naik turun disebabkan oleh oneksi jaringan tidak stabil.

\section{DAFTAR PUSTAKA}

[1] D. Prayama et al., "Sistem Monitoring Ruangan berbasis Raspberry Pi dan Motion Room Monitoring Sistem Based on Raspberry Pi and Motion," Poli Rekayasa, vol. 10, no. 2, pp. 24-35, 2015.

[2] R. Dawood, S. F. Qiana, and S. Muchallil, "Kelayakan Raspberry Pi sebagai web server : Perbandingan kinerja Nginx , Apache, dan Lighttpd pada platform Raspberry Pi, J. Rekayasa Elektr., vol. 11, no. 1, pp. 25-29, 2014.

[3] M. Rahayu, A. B. P, and A. 2012) Haritman, Erik(Dalam Stone, "Pengontrolan Alat Elektronika Melalui Media Wi-Fi Berbasis Raspberry Pi," Electrans, vol. 13, no. 1, pp. 35-42, 2014.

[4] A. Maslan, Belajar Cepat Teori, Praktek dan Simulasi Jaringan Komputer \& Internet, Pertama. Batam: Baduose, 2012.

[5] Rakhman, Raspberry Pi Mikrokontroller Mungil yang Serba Bisa, Pertama. Yogyakarta: Andi OFFSET, 2014.

[6] W. Donat, "Learn Raspberry Pi Programming with Python," Apress, vol. 7, no. 5, pp. 10-16, 2006.

[7] Raspberry P $i$ Foundation, "Raspberry P $i$ - Teach, Learn, and Make with Raspberry Pi," Www.Raspberrypi.Org, 2012. [Online]. Available: https://www.raspberrypi.org/.

[8] S. Prasad, P. Mahalakshmi, A. John, C. Sunder, and R. Swathi, "Smart Surveillance Monitoring Sistem Using Raspberry PI and PIR Sensor," Int. J. Comput. Sci. Inf. Technol., vol. 5, no. 6, pp. 7107-7109, 2014.
[9] Waloeya, Y.J., (2012). Seri Belajar Kilat Computer Networking, CV. Andi OFFSET. Yogyakarta.

[10] Bayu Prakasa. 2016. Automatisasi Smart Home Dengan Raspberry $P i$ dan Smartphone Android. STMIK GLOBAL INFORMATIKA MDP, Palembang

\section{BIODATA PENULIS}

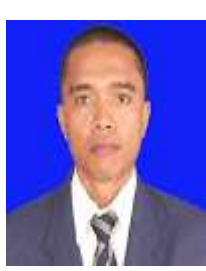

Andi Maslan

Dosen Universitas Putera Batam, mengajar Ilmu Komputer meliputi Jaringan Komputer dan Internet, Jaringan Nirkabel, Keamanan Jaringan dan Pemrograman Visual. Sedang Menjalani Pendidikan S3 di Universitas Tun on Husein Malaysia.

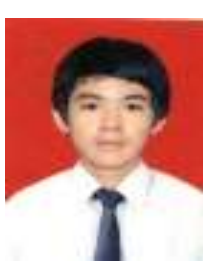

Hendri

Mahasiswa S1 Jurusan Teknik Informatika di Universitas Putera Batam lulusan Tahun 2015. Konsentrasi Bidang Hardware dan Software Kontrol Arduino dan Pemrograman Web. Bekerja di Perusahaan IT Tg. Pinang Kepulauan Riau.. 